Article

\title{
Research on 3D Painting in Virtual Reality to Improve Students' Motivation of 3D Animation Learning
}

\author{
Li-Hsing Ho ${ }^{1}$, Hung Sun ${ }^{2,3, *}$ and Tsun-Hung Tsai ${ }^{4}$ \\ 1 Department of Technology Management, Chung Hua University, Hsinchu 300, Taiwan; ho@chu.edu.tw \\ 2 Ph.D. Program of Technology Management, Chung Hua University, Hsinchu 300, Taiwan \\ 3 Department of Digital Multimedia Design, China University of Technology, Taipei City 116, Taiwan \\ 4 Department of Communications Design, Shih Chien University, Taipei City 104, Taiwan; \\ otaru@g2.usc.edu.tw \\ * Correspondence: arion3d@gm.cute.edu.tw; Tel.: +886-933-746191; Fax: +886-2-29349788
}

Received: 12 January 2019; Accepted: 12 March 2019; Published: 16 March 2019

\begin{abstract}
The purpose of this study was to investigate the use of 6-DoF high immersive virtual reality for stereoscopic spatial mapping to assess the impact of perceived spatial capabilities on 3D software learning motivation. This study wasn't a bound course with mandatory participation, and students were free to participate in the trial, and employed HTC VIVE, which provides highly immersive experiences, to elicit strong emotional responses. A total of 111 students from a university digital media department were invited to participate in a 3D VR painting experiment in which students created paintings using Google Tilt Brush. A 5-point scale based on the ARCS learning motivation model was adopted to collect student data. Perform a factor analysis of the data twice to select the appropriate factor $(p=0.000<0.05)$. Specifically, exploratory factor analysis was used to classify factors based on four constructs. The Cronbach alpha values of ARCS were 0.920, 0.929, 0.693 and 0.664 , respectively, both $>0.6$, which still indicate favorable reliability. The results show that immersive VR can promote students' motivation and interest in learning 3D animation. However, the practical application of this technology requires solving problems related to hardware and space.
\end{abstract}

Keywords: virtual reality; full immersive virtual reality; VR painting; ARCS; 3D animation learning

\section{Introduction}

\section{Research Motivation}

Since the development of computer-aided design (CAD) in the 1960s, three-dimensional (3D) animation has been widely applied in the film, construction, and gaming industries. From virtual reality (VR) to augmented reality (AR) applications, 3D animation serves as a crucial medium for creating visual content. In response to industrial and market needs, 3D animation techniques have become a core competency required of students in related fields.

Software for creating 3D animation features highly complex functions, resulting in a steep learning curve for beginners; therefore, methods for increasing the learning motivation of beginners is imperative. Because the initial learning scenario and student interest are primary factors that affect initial learning behavior [1], understanding how VR can be used to attract student interest is an essential consideration for teaching 3D animation.

With the advancements of computer hardware and software, new technology has often been applied to improve student learning. Neo and Neo [2] asserted that the use of multimedia technology is an innovative and effective teaching strategy that motivates learning and helps students to develop excellent problem-solving abilities. 
Blended base learning (BBL) has been adopted to reduce the difficulty of learning to use 3D animation software. Singh [3] maintained that the BBL concept views learning as a continual process rather than a single event. Compared with using a single learning method, blended learning features the benefits of different learning methods. Through approaches such as e-learning or online video viewing, an adequately designed BBL course can achieve more favorable learning outcomes than can conventional classroom learning. Learning to use 3D animation software requires a substantial amount of practice outside of class. Combining BBL with e-learning and online video viewing can provide a gaming-like learning environment that enhances student learning motivation and outcomes [4].

VR technology has undergone continual development, produced many applications, and is used by instructional designers and teachers to facilitate student learning. Considering the cost and ease of use of related equipment, most applications have mainly used desktop VR. Mikropoulos and Natsis [5] indicated that students and teachers have demonstrated an active attitude toward using VR in teaching environments. Presentations through educational virtual environments help students to understand complex concepts and reduce their misunderstanding. The two primary features of VR are immersion and presence. In particular, experiencing a sense of presence is a crucial factor that improves learning outcomes and encourages learners to further explore related learning. Merchant et al. [6] conducted a meta-analysis on 69 studies that employed VR learning tools to teach approximately 8000 high school and college students; the results indicated that, although VR teaching is highly effective, game-based learning can achieve particularly favorable learning outcomes.

Students in digital media design departments are generally proficient in creating 2D design and drawings. However, when they are introduced to 3D animation creation, they must visualize 3D space on a 2D computer screen; thus, the ability to reconceptualize spaces in alternate dimensions is pertinent to the ability to create 3D animation. Berney et al. [7] reported that, although teaching with 3D simulation was somewhat ineffective for students with excellent spatial abilities, it was highly effective for beginners with low spatial ability, allowing them to create complete 3D structures using dynamic visualizations and demonstrate favorable learning outcomes.

Most VR environments constitute a visual experience displayed on a computer screen. However, immersive VR enables users to completely immerse themselves in a computer-generated virtual environment. VR can be used repeatedly, is controllable, and generates an interactive and safe 3D environment in which users perceive that they have entered a virtual world [8]. Based on their use of a constructivist approach in their study, Huang et al. [9] stated that VR learning environments are applicable to extending the use of animation and multimedia for learning. Their research highlights a need for transition from conventional web-based multimedia learning to immersive, interactive, intuitive, and entertaining VR learning environments. By employing 3D models to simulate the real world, such learning environments can activate the imagination of users by enabling them to immerse themselves in interactions with 3D models.

Because of the complexity of creating 3D animation, methods for increasing the initial learning motivation of students is imperative. Renninger and Hidi [1] indicated that, because the initial learning scenario and interest might be antecedents that promote initial learning, the effects of interest on motivation and engagement can highlight the benefits of interest for all age groups. Developing interest in a topic can prompt motivation and meaningful engagement. The objective of the present study was to employ VR to examine and promote the development of student visual perception and affective skills, particularly by increasing learning motivation and interest. A 6-degree of freedom (6-DoF) room-scale VR was used to enable learners to experience a 3D virtual space when using Google Tilt Brush [10] to create 3D paintings. Because the immersive experience provided by a virtual environment can exclude external disturbances, users can focus on their vision and proprioception to perceive differences between 2D and 3D paintings. The proposed approach is expected to increase the motivation of students to use desktop computers to learn how to use 3D animation software. 


\section{Materials and Methods}

\subsection{Virtual Reality}

The earliest concept of VR can be attributed to Plato more than 2000 years ago. In the Republic, he presented the allegory of the cave, in which the environment inside and outside of the cave were divided into imaginative and real worlds, respectively. In 1962, a virtual device simulated cycling through the city. The machine features a 3D stereo sound system and immersive videos and enables users to experience vibration, smell, and breeze. Although it only provides a fixed riding route and viewing angle, it is considered the first immersive VR equipment to be produced [11].

The term "cyber space" was used in a science fiction story to describe VR [12]. VR technology today is based on the concept proposed by Jaron Lanier [13]. This company possessed numerous VR technology patents in the 1980s and developed the world's first head mounted display (HMD) and VR control glove. The Webster's new Universal Unabridged Dictionary (1989) defines virtual as "being in essence or effect, but not in fact" and reality as "the state or quality of being real. Something that exists independently of ideas concerning it. Something that constitutes a real or actual thing as distinguished from something that is merely apparent" [14,15].

Virtual Reality (VR) is a type of computer-simulated 3D environment that utilizes equipment enabling users to experience their own presence in the environment. This elicits a sense of presence that is perceivable but nonexistent in the simulated reality. In a VR environment, users can perceive a sense of immersion in a parallel world and interact with 3D objects by becoming digital avatars who interact with other users and digital avatars played by artificial intelligence systems. In addition to visual immersion, an ideal VR environment provides feedback in terms of sound, touch, smell, and proprioception. The essential features of VR are defined as the 3 I's, namely immersion, interaction, and imagination [16]. Another feature of VR is that it enables immersion in a synthetic environment instead of viewing the environment from an external perspective. The sense of immersion generated by VR depends on the ability of 3D images, head motion tracking, hand motion tracking, and stereophonic sound to provide a multisensory experience similar to that of visiting the virtual environment in person [17].

Hiem [18] and Yoh [19] have defined VR as technology that creates a computer-generated data set to replace sensory input and enable users to perceive their own presence in another space. Basically, VR denotes a theory that helps humans to realize their desire to escape from the real world by entering a virtual world; this technology provides a novel form of human-machine interaction with complete visual immersion.

The viewpoint of the present study concurs with that of Hew and Chung [20], who maintained that the features of VR are immersion, presence, and the ability to move freely, interact with virtual objects, and communicate with other users in the virtual environment. High-cost motion capture systems needs to be integrated in order to use VR to capture the body motion of users and project their avatars in the virtual environment. By combining proprioception technology, VR can further enhance the sense of immersion and presence. However, research exploring the integration of proprioception technology with motion-capturing technology for VR is still scant.

Despite the Sensorama serving as a prototype VR machine, it was not further developed. The drive to develop VR technology originated from the creation of flight simulators. In 1929, Edwin Link created the Link Trainer, which was the first ever commercial flight simulator [21]. From fighter simulators used during World War II to the space shuttle simulators used by astronauts, flight simulators differ substantially in terms of technological level but are created for the sole purpose of improving pilot safety records.

Since the 1960s, researchers have explored the application of 3D virtual environments in various fields. Ausburn and Ausburn [22] compared the effects of using desktop VR and static images on student learning outcomes, reporting that desktop VR was effective for improving student performance in environments with highly complex visual characteristics. For example, medical students can use 
virtual operating rooms to examine relevant equipment and tools before participating in clinical rotations. Khanal et al. [23] indicated that VR-based training for advanced cardiac life support can be adopted to supplement conventional training methods. Levac et al. [24] identified factors affecting the use of VR on physical therapy, including perceived usefulness and the self-efficacy of physicians, suggesting that, although VR has seen only a low application rate in physical therapy, this technology still demonstrates development potential in this field. Chan et al. [25] described a complex neurosurgery VR application that integrates high-resolution real-time imaging, force feedback devices, and tactile equipment. In their proposed application, the purpose of the physical simulation was to decompose biomechanical responses. However, an accurate tissue deformation simulation with high identifiability requires complex calculations. Based on contemporary technology, prerendered computer graphics can display highly precise models to simulate surgical techniques; however, its application to interactive simulation is impractical. Similarly, the quality of real-time 3D gaming effects is too low for performing meaningful neurosurgical simulations.

VR is also used to provide entertainment in museums and art galleries. In a VR environment, users can stroll in a museum or art gallery or view its collections without visiting the real place in person. Schofield et al. [26] used a mobile phone and headset that enable users to view an exhibition from a fixed point in a VR platform; this prevents viewers from missing any essential or interesting exhibition content. The platform successfully displayed cultural heritage backgrounds to the viewers, verifying the feasibility of using the proposed VR approach to disseminate rich information and attract user attention. Even the use of immersive desktop VR can enhance user interest and memory [27]. The sense of immersion enabled by VR provides users with a perceptual experience similar to that of personally visiting the location, thus creating an almost real experience that can be employed to promote concepts such as marine conservation [28].

VR technology is primarily applied to improve the development of products in the entertainment industry, such as games and films. However, researchers in other fields have evaluated the feasibility of VR applications. VR systems are mostly designed for direct human use. When VR systems are used for special scenarios, such as research on animal or bee vision, additional factors must be considered [29].

\subsection{Virtual Reality and Learning Motivation}

Motivation is a primary factor affecting learning. Learning is also driven by motivation. Students with learning motivation demonstrate relatively high learning efficiency. Instructional designers and teachers can use various types of techniques to offer courses and activities that attract the interest of students, thereby improving their learning motivation and outcomes [30].

Mayer [31] indicated that certain advantages of an excellent curriculum design may only be achieved through specific techniques because such techniques enable the application of teaching methods that cannot otherwise be implemented. An educational virtual environment, or virtual learning environment (VLE), is a teaching approach based on virtual environments. This approach provides individuals or groups with virtual experiences, helping them to acquire knowledge as if they were in the real world or providing incentives when learners achieve a specific learning outcome [5]. A VLE is a prevalent approach but does not by itself lead to learning; rather, the cognitive processes of the learner are the primary factor determining learning outcomes. Shin [32] maintained that a VLE entails effectively eliciting a sense of immersion and presence and utilizing affective support to ensure feasibility and the provision of high-quality content. Furthermore, users possess a certain level of acceptance toward the affordances of VR technology, and ensuring user acceptance is a method that effectively promotes user motivation and affective support.

Potkonjak et al. [33] suggested that, because of the current technical level, virtual laboratories and simulators are commonly used only as tools for training engineering students, whereas practical experiments continue to rely on physical equipment. Bonde et al. [34] invited psychologists to research 160 students from Stanford University and the Technical University of Denmark. The students were divided into two groups, one of which received teaching through a virtual laboratory simulation and 
the other of which was subject to conventional learning. Their results revealed that, with the same amount of learning time, the virtual laboratory simulation improved students' learning outcome by $76 \%$; moreover, this value was further improved to $101 \%$ through instructors' tutoring, effectively doubling the improvement rate of conventional learning.

Compared with learning in a 2D animation environment, that in an immersive 3D VLE can improve student motivation and interest. Through interaction and repetition, VR can also facilitate knowledge retention and increase student motivation [35]. The 3 I's of VR technology are the main factors attracting and encouraging students to learn in a VLE. Kartiko et al. [36] discovered that even using the simplest visual material in a virtual world can elicit an adequate degree of presence and affectation in a VR application. In other words, using a simple animation virtual actor can exert an effect similar to that of a complex animation visual actor in a VLE.

Participants in the present study used simple drawing tools in Google Tilt Brush [10] to create paintings with simple lines while experiencing the creation process and interacting with the virtual space. They were expected to exhibit a stronger emotional response and higher level of engagement, thereby developing favorable emotional motivation.

\subsection{Spatial Ability and Learning 3D Application Software}

Computer-generated images created using 3D software have been prevalently used in movies, animations, and games. Creating the content of $\mathrm{VR}, \mathrm{AR}$, and mixed reality applications also requires the use of 3D software. Conventional teaching generally employs print materials or physical models; however, this approach does not address the application of 3D visual space [37]. Using 3D software for teaching on desktop computers also poses similar problems. Lee et al. [38] indicated that, in a desktop VR learning environment, spatial ability did not exert a moderating effect on learning outcomes.

Learning 3D animation software is a visual learning process. Höffler [39] pointed out that, when using visual learning, learners' spatial cognition of 3D objects is very important. Learners with high spatial ability are still better than learners with low space ability. There is better learning, but the difference is reduced. Spatial awareness is strongly correlated with the development of intelligence and logical reasoning abilities and is a core competence required for developing and using 3D animation software [37]. "Spatial visualization ability refers to individuals' ability to play, rotate, twist, or reverse images to reflect the stimulation effect in the mind." Using VR technology can also improve the spatial awareness of its users [40].

In VR, spatial immersion denotes the perception of a physical presence that exists in a nonphysical world. The primary motive of using VR is that it provides the experience of a scenario that is otherwise impossible to experience in the real world [2]. Furthermore, 6-DoF room-scale VR enables users to experience their own presence in another space, allowing them to enter a virtual environment while perceiving a sense of presence that is similar to that experienced in the real world [41]. As the primary component of VR, a virtual world is an imaginary space simulated using a computer. When users enter a virtual world and experience a sense of immersion through VR, they perceive their own presence in the virtual or alternative world [15]. Matthew, Nathan and Sarah [42] argued that "self-reported imagery ability can predict reports of spatial presence when experiencing a virtual environment through a HMD" indicates that visual space images may be important, but require further measurement.

When VR is applied to teaching, even desktop VR can simulate sensory stimuli by displaying a virtual object on the screen; the presence of the object provides users with a sense of immersion and guides them to enter the virtual scenario [43]. Desktop VR does not feature spatial immersion; therefore, its operating method and the perspective it offers are similar to those of 3D video games or 3D animation software. The present study did not adopt desktop VR. Another type of VR is HMD VR (e.g., a VR cardboard device attached to a mobile phone) in which the user cannot move or sense movement within the simulation; this type of VR has been verified to improve the ability of users to perceive 3D objects [40]. Greenwald et al. [44] maintained that VR reinforces learning 
through immersive experiences involving spatial interactions with virtual objects. A user-oriented 3D exploration can improve users' understanding of a specific topic. However, when using HMD VR, users may experience a gap between their virtual and actual perceptions, thereby impeding their understanding of VR content. Huk, Steinke and Floto [45] found that participants with high spatial ability had a more positive attitude towards complex 3D images, and Huk [46] pointed out that students with low spatial ability were cognitively overloaded by the existence of 3D models. Students with high space ability benefit from them.

Self-motion illusions in VR enhance the sense of reality in a virtual environment. However, user experiences may vary because movements of the human body are highly complex, which can result in actions of varying frequency and intensity caused by differences in height and weight of the human body as well as the effects of movement speed and ground reaction force. Riecke et al. [47] explored movement in VR to identify a method for preventing cybersickness, which is caused by conflict between a user's sensory systems [48]. Although similar problems may arise due to factors such as field of view, geometric field of view, and image delay, movement is currently the primary problem that must be addressed regarding motion sickness in VR; creators of HMD VR that combine mobile phones with headsets have experienced great difficulty overcoming this problem.

\subsection{Research Method}

Before the experiment was conducted in this study, test the combination of other VR controllers, HMDs, and application software to shape the 3D virtual space (Figure 1).

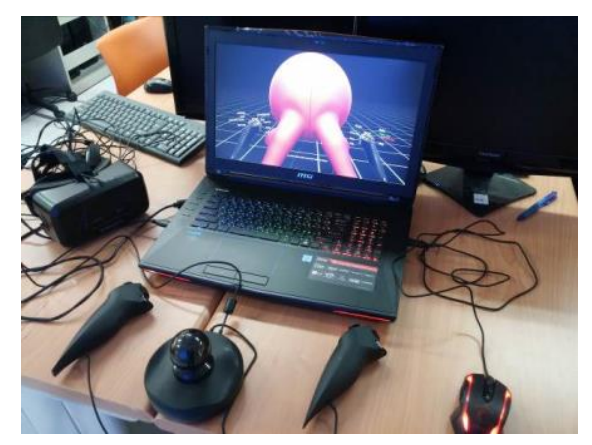

Figure 1. Other VR controllers, HMD and software testing.

Oculus Rift DK2 only features a three-axis gyroscope, meaning that users cannot bend their body or move closer to a target to observe and configure the target. When used in combination with a 6-DoF controller, the HMD leads to a bizarre experience in which users can only turn their head but cannot move their body in a 3D virtual environment. Consequently, the sense of immersion is disrupted when users attempt movement. Shin [32] suggested that users possess a certain level of acceptance toward the affordance of VR technology and that ensuring user acceptance facilitates eliciting user motivation and affective support. In addition, user perception is a prominent factor affecting the immersive quality of an experience, indicating that immersion affects user learning experiences.

This study adopted the HTC Vive and Google Tilt Brush as testing tools for creating 3D paintings in a VR environment (Figure 2). The HTC Vive is currently one of the most advanced VR systems for providing an immersive experience. Tilt Brush is a room-scale 3D painting virtual reality application available from Google. With the HTC Vive HMD, users can view a virtual space through the display and use a VR controller to freely select different brushes and coloring tools. The entire virtual space serves as a canvas, enabling users to create all types of paintings in midair. Users can also freely walk within the virtual space to fully experience the process of creating a 3D painting. 


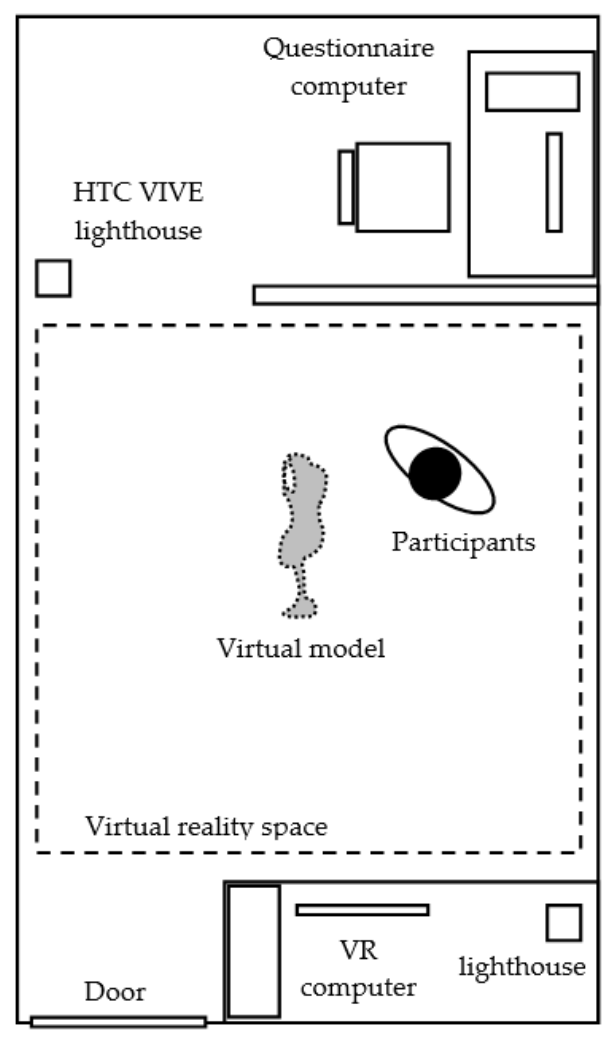

Figure 2. Virtual reality experimental environment diagram.

\subsubsection{Participants}

Participants were 111 students from a university department of digital media design, of which 45 were female students (40.5\%) and 66 were male students (59.5\%). The students were between the ages of 19 and 21 years. Table 1 displays information on the basic capabilities of the students.

Table 1. Basic information on the capabilities of participants.

\begin{tabular}{|c|c|c|c|c|c|c|c|c|c|c|c|}
\hline \multirow[b]{2}{*}{ No. } & \multirow[b]{2}{*}{ Questionnaire Items } & \multicolumn{10}{|c|}{ Number of Questionnaire Responses } \\
\hline & & $\begin{array}{c}\text { Answer: } \\
1\end{array}$ & $(\%)$ & $\begin{array}{l}\text { Answer: } \\
\quad 2\end{array}$ & $(\%)$ & $\begin{array}{l}\text { Answer: } \\
3\end{array}$ & $(\%)$ & $\begin{array}{c}\text { Answer: } \\
4\end{array}$ & $(\%)$ & $\begin{array}{l}\text { Answer: } \\
5\end{array}$ & $(\%)$ \\
\hline 1 & $\begin{array}{l}\text { Assess the extent of your } \\
\text { 2D drawing or design. }\end{array}$ & 11 & 9.9 & 21 & 18.9 & 39 & 35.1 & 32 & 28.8 & 8 & 7.2 \\
\hline 2 & $\begin{array}{l}\text { I feel that learning 3D } \\
\text { software is not easy. }\end{array}$ & 29 & 26.1 & 27 & 24.3 & 28 & 25.3 & 23 & 20.7 & 4 & 3.6 \\
\hline 3 & $\begin{array}{l}\text { For me, there is no } \\
\text { barrier to converting 2D } \\
\text { images to 3D objects. }\end{array}$ & 13 & 11.7 & 21 & 18.9 & 46 & 41.4 & 25 & 22.5 & 6 & 5.4 \\
\hline
\end{tabular}

\subsubsection{Apparatus}

The questionnaires (shown as Table A1) were presented on a 22" LCD computer screen $(1920 \times 1080$ pixels, $60 \mathrm{~Hz})$ using online form by Chrome browser. Responses were collected through mouse and keyboard. A computer graphic work station connected to the VR HMD.

\subsubsection{Procedure}

Participants were divided into groups of 3-4 students, and each underwent the same procedure. Each group of participants began by developing an understanding of the operating procedure and practicing using it before creating their own painting. Specifically, participants first watched an introductory video that taught them how to use Google Tilt Brush. Next, they wore the VR HMD and 
held a controller while a researcher explained the function of each button; participants were permitted 5 min of practice to familiarize themselves with the controller. Finally, they were each asked to paint in a predetermined VR scenario for $10 \mathrm{~min}$, All participants use the same preset VR scene to ensure that they have the same benchmark as a basis for VR painting to avoid users being confused in an empty VR environment. During this process, the researchers monitored participant safety conditions and ensured that no one stepped on the ultra-high-definition cables.

To ensure that participants did not forget their objective in the 3D virtual environment, the built-in clothing design model in the painting software was used as a reference for them to create paintings (Figure 3). Participants could walk around the reference model in the VR environment to redesign and create clothing. Those who were awaiting their turn to use the software could view the live VR operations of other students on a computer screen (Figure 4). Most participants were able to produce a painting that they were satisfied with (Figure 5). Some students with excellent spatial ability were able to complete their paintings without using the reference model (Figure 6).

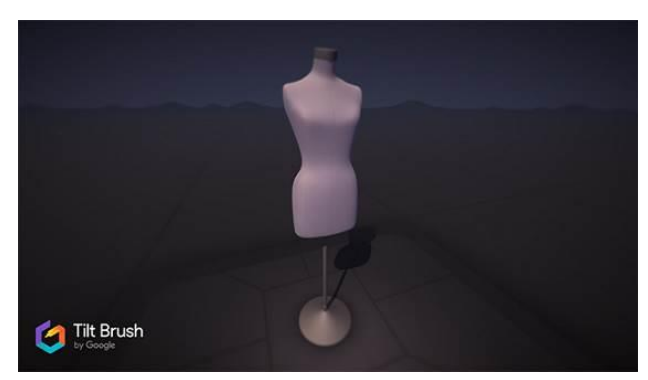

Figure 3. The reference model for 3D painting.

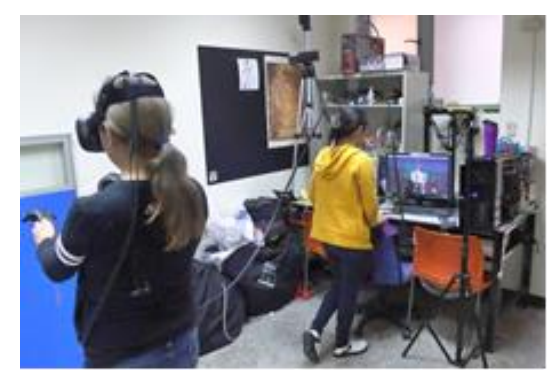

Figure 4. Waiters can watch the live VR operation on the screen.

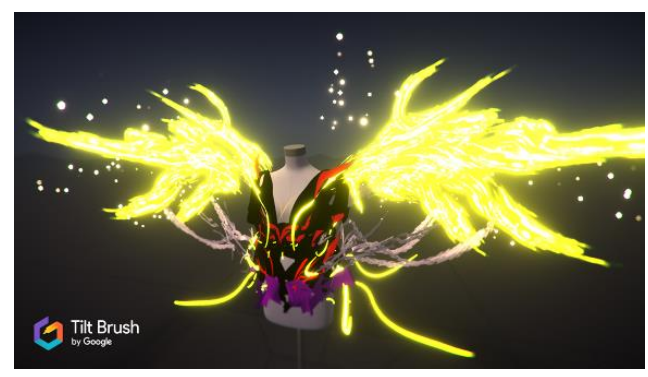

Figure 5. Results of a regular student. 


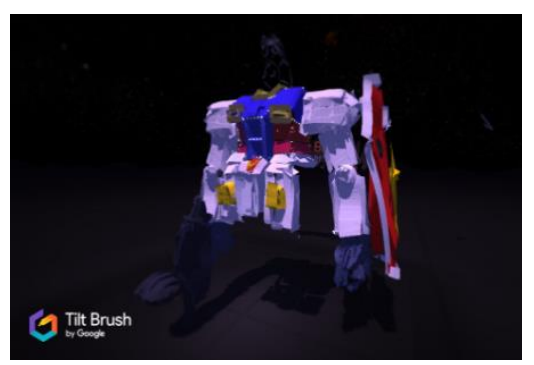

Figure 6. Results of a student with superb spatial ability.

After participants had produced their paintings, they were asked to complete a questionnaire based on the ARCS model [30]. ARCS refers to the four elements of Attention, Relevance, Confidence, and Satisfaction. It emphasizes that the motivation of the learner must cooperate with the use of these four elements to achieve the role of stimulating students' learning. The collected data were used to examine the effect of VR on the emotional response of students to the learning experience.

\subsubsection{Hygienic}

With the exception of the cardboard-based VR headset, most VR learning equipment tools were shared among participants. Because the VR HMD requires close contact with the face, relevant hygiene concerns were required to be addressed. Disposable paddings were prepared and placed under the eyepiece region of the HMD (Figure 7). The padding was replaced each time that the HMD was used by a different student.

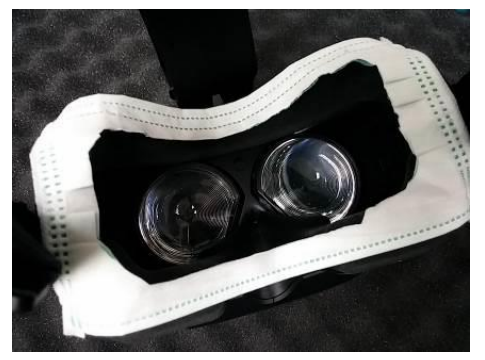

Figure 7. We have made correction according to the Reviewer's comments.

\section{Results}

After painting with VR, the students were asked to fill in the "Virtual Reality Painting and 3D Learning Motivation" questionnaire, which was based on the Likert Scale. The Likert Scale was invented by psychiatrist Rensis Likert and is primarily used to measure the subjective or objective evaluations of an item description by participants; these evaluations are usually presented according to their degree of agreement with the description.

A total of 111 students participated in this experiment, the duration for which was approximately four weeks. The number of valid responses was 109. Participant demographics are listed in Table 1. None of the participants had prior experience with 6-DoF room-scale VR equipment.

Conduct a factor analysis and organize the questionnaire items into several constructs. In the first factor analysis, the Kaiser-Meyer-Olkin (KMO) value was 0.872 (Table 2), indicating that the collected data were meritorious for performing factor analysis. The Bartlett's test of sphericity revealed that the approximated chi-square value was 2095.158 and achieved significance $(\mathrm{df}=465 ; p=0.000<0.05)$. The results indicated that cofactors existed among the 31 items in the questionnaire, meaning that the collected data were suitable for factor analysis (Table 3). 
Table 2. Kaiser-Meyer-Olkin and Bartlett's Test in the first factor analysis.

\begin{tabular}{ccc}
\hline Kaiser-Meyer-Olkin Measure of Sampling Adequacy & $\mathbf{0 . 8 7 2}$ \\
\hline & Approx. Chi-Square & 2095.158 \\
Bartlett's Test of Sphericity & $\mathrm{df}$ & 465 \\
& Sig. & 0.000 \\
\hline
\end{tabular}

Table 3. Total variance explained in the first factor analysis.

\begin{tabular}{ccccccc}
\hline \multirow{2}{*}{ Component } & \multicolumn{2}{c}{ Extraction Sums of Squared Loadings } & \multicolumn{2}{c}{ Rotation Sums of Squared Loadings } \\
\cline { 2 - 6 } & Total & \% of Variance & Cumulative \% & Total & \% of Variance & Cumulative \% \\
\hline 1 & 11.289 & 36.417 & 36.417 & 11.289 & 36.417 & 36.417 \\
2 & 2.756 & 8.889 & 45.306 & 2.756 & 8.889 & 45.306 \\
3 & 2.028 & 6.541 & 51.847 & 2.028 & 6.541 & 51.847 \\
4 & 1.685 & 5.437 & 57.284 & 1.685 & 5.437 & 57.284 \\
5 & 1.455 & 4.693 & 61.977 & 1.455 & 4.693 & 61.977 \\
6 & 1.290 & 4.161 & 66.138 & 1.290 & 4.161 & 66.138 \\
7 & 1.068 & 3.444 & 69.582 & 1.068 & 3.444 & 69.582 \\
\hline
\end{tabular}

The data were subjected to varimax rotation to obtain a rotated component matrix. When the number of components was unlimited, seven components that had an eigenvalue of $>1$ and contained $6,7,6,5,2,3$, and 2 items were extracted. The cumulative variance was 69.582. Components 5 and 7 contained too few items and were thus excluded from the subsequent factor analysis.

Table 4 lists the results of the second factor analysis. The KMO value was 0.872 , and the approximated chi-square value was significant $(\mathrm{df}=456 ; p=0.000<0.05)$ at 2095.158 .

Table 4. KMO and Bartlett's Test in the 2nd factor analysis.

\begin{tabular}{ccc}
\hline \multicolumn{2}{c}{ Kaiser-Meyer-Olkin Measure of Sampling Adequacy } & $\mathbf{0 . 8 7 6}$ \\
\hline & Approx. Chi-Square & 1822.304 \\
Bartlett's Test of Sphericity & df & 351 \\
& Sig. & 0.000 \\
\hline
\end{tabular}

Five constructs were extracted from the second factor analysis. A comparison of the items in each construct revealed that two of the constructs contained similar items; therefore, an exploratory factor analysis was performed. The number of constructs was limited to four to concur with the component of the ARCS model. The results revealed that the KMO value was 0.876 , the approximated chi-square value was significant $(\mathrm{df}=351 ; p=0.000<0.05)$ at 1822.403 , and the cumulative explained variance was 60.647 (Table 5). Table 6 displays The Cronbach's $\alpha$ values were all $>0.6$, which still indicate favorable reliability.

Table 5. Total variance explained in the exploratory factor analysis.

\begin{tabular}{ccccccc}
\hline \multirow{2}{*}{ Component } & \multicolumn{2}{c}{ Extraction Sums of Squared Loadings } & \multicolumn{2}{c}{ Rotation Sums of Squared Loadings } \\
\cline { 2 - 7 } & Total & \% of Variance & Cumulative \% & Total & \% of Variance & Cumulative \% \\
\hline 1 & 10.398 & 38.509 & 38.509 & 10.398 & 38.509 & 38.509 \\
2 & 2.705 & 10.019 & 48.528 & 2.705 & 10.019 & 48.528 \\
3 & 1.683 & 6.233 & 54.761 & 1.683 & 6.233 & 54.761 \\
4 & 1.589 & 5.886 & 60.647 & 1.589 & 5.886 & 60.647 \\
\hline
\end{tabular}


Table 6. Reliability analysis of the four constructs.

\begin{tabular}{cccc}
\hline Constructs & Cronbach's Alpha & $\begin{array}{c}\text { Cronbach's Alpha Based on } \\
\text { Standardized Items }\end{array}$ & N of Items \\
\hline Attention (A) & 0.920 & 0.921 & 12 \\
Relevance (R) & 0.929 & 0.930 & 6 \\
Confidence (C) & 0.693 & 0.699 & 5 \\
Satisfaction (S) & 0.664 & 0.664 & 3 \\
\hline
\end{tabular}

\section{Discussion}

The results of this study concur with those reported by Devon [49], which indicated that VR exerted a notable effect on emotion. Participants became more active in their learning, and their negative emotions decreased. Compared with instructional videos, VR learning led to more favorable testing results. The improved learning performance of students may be attributable to 3D immersion or interaction with the VR environment. The present study inferred that VR poses unique advantages for attracting student attention and interest. The sense of immersion and spatial presence provided through VR can exclude external disturbances, thereby improving student concentration. Furthermore, 3D VR content and the current popularity of VR increase the appeal of this technology for students. Therefore, the reliability of the first two constructs of the ARCS model (namely attention and relevance) was $>0.90$, which surpassed the Cronbach's $\alpha$ threshold of 0.7 , indicating high reliability. The reliability of the remaining constructs (namely confidence and satisfaction) was between 0.6 and 0.7 , which indicated an acceptable level of reliability. The lower reliability of these constructs may be attributable to the relatively short period of time allocated to each student for using the VR program and the fact that the VR program was not included in the official curriculum. VR is currently primarily used in the entertainment industry to create products such as VR games and videos. When VR games are not used to design experiential activities, student motivation and satisfaction regarding participation in such activities may be lower.

This study verified that using 6-DoF room-scale VR equipment to create 3D paintings increase student interest and confidence in learning 3D animation. Most participants agreed that, when using VR equipment, they felt as if they were physically present in another dimension; this experience cannot be achieved through desktop VR. Participant reactions revealed that most of them could immediately immerse themselves in the virtual environment. Only few participants experienced slight cybersickness. The occurrence of cybersickness might be attributable to decreases in frame rate caused by the excessive use of snow and spark brushes, the sense of enclosure induced by the large number of particles effect surrounding each participant, the incompatibility of the eyepiece with glasses worn by near-sighted students, or the inadequate configuration of the distance between the two viewing lenses of the HMD. Conventionally, the movement speed of the camera is reduced to alleviate cybersickness experienced by users of immersive VR who cannot move their body. However, this problem can be overlooked with VR with complete DoF.

Notably, two of the participants insisted on using a 2D perspective to create 3D paintings, even after viewing the introduction video and demonstration on VR. Their paintings became distorted when viewed from different angles; however, the participants could not comprehend the 3D perspective and refused to alter their painting approach. This incident highlighted one potential difficulty of teaching students how to use 3D animation software.

Participants volunteered for this study on their own free will. The researchers provided information regarding this study to eight classes, spanning four grades, in a university department of digital media design. Half of the students had never used VR applications and were completely uninterested in VR paintings. Their reaction might be attributable to the irrelevance of the study to VR gaming.

In this study, only a single set of VR equipment was available. Each group of 3-4 participants took turns using the device. The duration of the entire process, from first viewing the introduction video to 
completing the painting, was $1-1.5 \mathrm{~h}$ for all students. Considering that the typical size of classes in Taiwan is 50-60 students, at least 10 sets of VR equipment are required to establish a VLE. Therefore, implementing VR teaching requires that sufficient space and equipment be available. Furthermore, users should operate immersive VR equipment in the presence of others who can ensure their safety. Relevant hygiene concerns should also be considered when multiple people are using an HMD.

\section{Conclusions}

Overall, immersion VR is highly attractive to both teachers and students. However, participants required assistance from others to adjust and put on the device. Additionally, operation methods were required to be explained to enable users to operate the software without difficulty [50]. Using 6-DoF room-scale VR requires a large, independent space, and the complete set of equipment is expensive. Furthermore, it can only be used by one user at a time. If multiple sets of equipment are set up, then they must be isolated to prevent interference from dual lighthouse (laser tracking).

As long as spatial constraints and the problems with equipment can be overcome, 6-DoF room-scale VR is suitable for incorporation in 3D-assisted teaching to enable students to experience and develop their spatial ability.

To generate and sustain the attention, maintain the interest, trigger the motivation to explore, and meet the teaching and learning requirements of users [51], immersion experience must be combined with the operation of 3D model construction or animation production software using VR to facilitate student engagement with $3 \mathrm{D}$ animation learning software.

\section{Limitations and Future Research}

The limitation of this study is that the technology used is HTC VIVE, which requires considerable independent space and needs to isolate the Lighjthouse for each VR device. On the other hand, Desktop VR uses mouse control (student has a lot of experience). However, Google Tilt Brush doesn't have a PC version, so the software features and the handheld controller and interface in the immersive VR state are new and not very intuitive. In addition, Wii Remote, Wii Balance Board, Microsoft Kinect, Leap Motion, etc. are used as VR interactive controllers [52-55], mainly to solve the operability of Desktop VR, Cave VR or Headset VR. These input devices, for the user, are still not familiar with the usual operational patterns and need to be re-learned and adapted. Because conducting such research is time consuming, future research should use more advanced techniques to study the value of immersive VR. Finally, additional factors can be considered to further examine the effect of VR on learning outcomes. These include use time, type of VR equipment (e.g., Headset VR, room-scale immersive VR, Even Mix Reality Headset), and inconvenience of installing a large amount of equipment. This should improve the flexibility and mobility of VR equipment.

Numerous scholars have maintained that immersive VR equipment is expensive and cannot provide students with a completely virtual experience. However, some VR products are less expensive and require little space for operation; moreover, the resolution of commercially available HMDs is sufficient for operating 3D animation software in a VR environment. For example, the latest generation of VR HMD (e.g., HTC Vive Focus) with inside-out tracking technology comes with a single handheld controller for non-6-DoF VR applications. The HTC Vive Pro enables two users to simultaneously participate in VR activities in the same place. Oculus Quest is a 6-DoF room-scale all-in-one system that does not have cables. Finally, mixed reality HMDs also utilize inside-out technology. Future studies can employ the aforementioned products and technology.

Author Contributions: L.-H.H.; supervision, H.S.; conceived and performed the experiments, analyzed the literature background and the data, and wrote the paper, T.-H.T., data sorting.

Acknowledgments: Some of the materials in this article are presented as oral presentations entitled "3D Painting Research in Virtual Reality to Improve Students' Motivation for 3D Animation Learning", 2nd Eurasian Education Innovation Conference 2019.

Conflicts of Interest: The authors declare no conflict of interest. 


\section{Appendix A}

Table A1. Number of questionnaire responses to the ARCS scale.

\begin{tabular}{|c|c|c|c|c|c|c|c|c|c|c|c|}
\hline \multirow[b]{2}{*}{ No. } & \multirow[b]{2}{*}{ Questionnaire Items } & \multicolumn{10}{|c|}{ Number of Questionnaire Responses } \\
\hline & & $\begin{array}{c}\text { Answer: } \\
1\end{array}$ & $(\%)$ & $\begin{array}{l}\text { Answer: } \\
2\end{array}$ & $(\%)$ & $\begin{array}{l}\text { Answer: } \\
3\end{array}$ & $(\%)$ & $\begin{array}{l}\text { Answer: } \\
\quad 4\end{array}$ & $(\%)$ & $\begin{array}{l}\text { Answer: } \\
5\end{array}$ & $(\%)$ \\
\hline 1 & $\begin{array}{l}\text { The first time I touched } \\
\text { the VR drawing, I found } \\
\text { the content interesting } \\
\text { and immediately caught } \\
\text { my attention. }\end{array}$ & 69 & 62.2 & 29 & 26.1 & 11 & 9.9 & 2 & 1.8 & 0 & 0 \\
\hline 2 & $\begin{array}{l}\text { The VR drawing method } \\
\text { is compelling. }\end{array}$ & 67 & 60.4 & 31 & 27.9 & 9 & 8.1 & 4 & 3.6 & 0 & 0 \\
\hline 3 & $\begin{array}{l}\text { The VR immersion } \\
\text { environment can help } \\
\text { me maintain my } \\
\text { attention. }\end{array}$ & 56 & 50.5 & 40 & 36 & 14 & 12.6 & 1 & 0.9 & 0 & 0 \\
\hline 4 & $\begin{array}{l}\text { The content of VR } \\
\text { drawing materials is } \\
\text { very abstract, and it is } \\
\text { very difficult to keep } \\
\text { attention. }\end{array}$ & 12 & 10.8 & 10 & 9 & 36 & 32.4 & 33 & 29.7 & 20 & 18 \\
\hline 5 & $\begin{array}{l}\text { The way of drawing } \\
\text { with VR is boring and } \\
\text { unattractive. }\end{array}$ & 5 & 4.5 & 5 & 4.5 & 7 & 6.3 & 33 & 29.7 & 61 & 55 \\
\hline 6 & $\begin{array}{l}\text { Drawing in VR can help } \\
\text { me stay focused. }\end{array}$ & 39 & 35.8 & 37 & 33.9 & 28 & 25.7 & 5 & 4.6 & 0 & 0 \\
\hline 7 & $\begin{array}{l}\text { I am curious about the } \\
\text { way and content of } \\
\text { drawing with VR. }\end{array}$ & 62 & 56.9 & 33 & 30.3 & 10 & 9.2 & 2 & 1.8 & 2 & 1.8 \\
\hline 8 & $\begin{array}{l}\text { Repeating the same } \\
\text { content all the time, } \\
\text { sometimes it makes me } \\
\text { bored. }\end{array}$ & 7 & 6.4 & 12 & 10.9 & 27 & 24.5 & 33 & 30 & 31 & 28.2 \\
\hline 9 & $\begin{array}{l}\text { I learned amazed or } \\
\text { unexpected content } \\
\text { from the way I was } \\
\text { drawing with VR. }\end{array}$ & 60 & 54.5 & 32 & 29.1 & 13 & 11.8 & 4 & 3.6 & 1 & 0.9 \\
\hline 10 & $\begin{array}{l}\text { The way you draw with } \\
\text { VR can be boring. }\end{array}$ & 4 & 3.6 & 3 & 2.7 & 9 & 8.1 & 36 & 32.4 & 59 & 53.2 \\
\hline 11 & $\begin{array}{l}\text { The way VR is drawn is } \\
\text { related to what I have } \\
\text { learned before. }\end{array}$ & 15 & 13.5 & 26 & 23.4 & 41 & 36.9 & 22 & 19.8 & 7 & 6.3 \\
\hline 12 & $\begin{array}{l}\text { I think it's important to } \\
\text { apply images, } \\
\text { animations, text or } \\
\text { movies in VR drawing. }\end{array}$ & 38 & 34.2 & 39 & 35.1 & 31 & 27.9 & 3 & 2.7 & 0 & 0 \\
\hline 13 & $\begin{array}{l}\text { It's important for me to } \\
\text { have such a VR drawing } \\
\text { style in my learning } \\
\text { activities. }\end{array}$ & 37 & 33.3 & 42 & 37.8 & 28 & 25.2 & 4 & 3.6 & 0 & 0 \\
\hline 14 & $\begin{array}{l}\text { The VR drawing method } \\
\text { allows me to increase } \\
\text { my interest in 3D and } \\
\text { design. }\end{array}$ & 54 & 48.6 & 39 & 35.1 & 17 & 15.3 & 1 & 0.9 & 0 & 0 \\
\hline 15 & $\begin{array}{l}\text { Using VR drawing } \\
\text { methods and content } \\
\text { will allow me to learn to } \\
\text { apply relevant } \\
\text { knowledge. }\end{array}$ & 42 & 37.8 & 47 & 42.3 & 21 & 18.9 & 0 & 0 & 1 & 0.9 \\
\hline 16 & $\begin{array}{l}\text { I use VR drawing } \\
\text { methods and content to } \\
\text { make me prefer to learn }\end{array}$ & 51 & 45.9 & 38 & 34.2 & 21 & 18.9 & 1 & 0.9 & 0 & 0 \\
\hline
\end{tabular}


Table A1. Cont.

\begin{tabular}{|c|c|c|c|c|c|c|c|c|c|c|c|}
\hline \multirow[b]{2}{*}{ No. } & \multirow[b]{2}{*}{ Questionnaire Items } & \multicolumn{10}{|c|}{ Number of Questionnaire Responses } \\
\hline & & $\begin{array}{c}\text { Answer: } \\
1\end{array}$ & $(\%)$ & $\begin{array}{l}\text { Answer: } \\
2\end{array}$ & $(\%)$ & $\begin{array}{c}\text { Answer: } \\
3\end{array}$ & $(\%)$ & $\begin{array}{c}\text { Answer: } \\
4\end{array}$ & $(\%)$ & $\begin{array}{c}\text { Answer: } \\
5\end{array}$ & $(\%)$ \\
\hline 17 & $\begin{array}{l}\text { The way and content of } \\
\text { VR drawing is not } \\
\text { important, because I } \\
\text { already use it. }\end{array}$ & 5 & 4.5 & 2 & 1.8 & 10 & 9 & 30 & 27 & 64 & 57.7 \\
\hline 18 & $\begin{array}{l}\text { The way and content of } \\
\text { VR drawing is related to } \\
\text { what I have seen or } \\
\text { thought about. }\end{array}$ & 42 & 37.8 & 43 & 38.7 & 23 & 20.7 & 2 & 1.8 & 1 & 0.9 \\
\hline 19 & $\begin{array}{l}\text { I think the use of VR } \\
\text { drawing is easier and } \\
\text { easier. }\end{array}$ & 21 & 18.9 & 31 & 27.9 & 39 & 35.1 & 16 & 14.4 & 4 & 3.6 \\
\hline 20 & $\begin{array}{l}\text { Drawing with VR is } \\
\text { harder to understand } \\
\text { than I imagined. }\end{array}$ & 8 & 7.2 & 20 & 18 & 42 & 37.8 & 28 & 25.5 & 13 & 11.7 \\
\hline 21 & $\begin{array}{c}\text { After using VR's } \\
\text { drawing method, I } \\
\text { became more confident } \\
\text { in understanding 3D } \\
\text { and design. }\end{array}$ & 27 & 24.3 & 36 & 32.4 & 43 & 38.7 & 4 & 3.6 & 1 & 0.9 \\
\hline 22 & $\begin{array}{l}\text { The VR drawing method } \\
\text { provides a lot of content, } \\
\text { so I don't know and } \\
\text { remember what is } \\
\text { important. }\end{array}$ & 10 & 9 & 11 & 9.9 & 54 & 48.6 & 26 & 23.4 & 10 & 9 \\
\hline 23 & $\begin{array}{l}\text { With such a way and } \\
\text { content of VR drawing, I } \\
\text { am more confident in } \\
\text { understanding 3D and } \\
\text { design. }\end{array}$ & 27 & 24.3 & 46 & 41.4 & 34 & 30.6 & 4 & 3.6 & 0 & 0 \\
\hline 24 & $\begin{array}{l}\text { The way VR drawing is } \\
\text { too difficult for me. }\end{array}$ & 6 & 5.4 & 15 & 13.5 & 30 & 27 & 40 & 36 & 21 & 18 \\
\hline 25 & $\begin{array}{l}\text { There are a lot of ways I } \\
\text { can't really understand } \\
\text { how VR plots work. }\end{array}$ & 4 & 3.6 & 14 & 12.6 & 36 & 32.4 & 38 & 34.2 & 19 & 17.1 \\
\hline 26 & $\begin{array}{l}\text { After using the VR } \\
\text { drawing method, I feel } \\
\text { very satisfied. }\end{array}$ & 58 & 52.3 & 40 & 36 & 11 & 9.9 & 1 & 0.9 & 1 & 0.9 \\
\hline 27 & $\begin{array}{l}\text { After using the drawing } \\
\text { method of VR, I feel that } \\
\text { I should be more } \\
\text { familiar with this aspect } \\
\text { of knowledge. }\end{array}$ & 47 & 42.3 & 49 & 44.1 & 14 & 12.6 & 1 & 0.9 & 0 & 0 \\
\hline 28 & $\begin{array}{l}\text { I really like to use VR } \\
\text { drawing methods to } \\
\text { create works. }\end{array}$ & 51 & 45.9 & 33 & 29.7 & 23 & 20.7 & 4 & 3.6 & 0 & 0 \\
\hline 29 & $\begin{array}{l}\text { After using the VR } \\
\text { drawing method, I was } \\
\text { affirmed and } \\
\text { encouraged. }\end{array}$ & 34 & 30.6 & 39 & 35.1 & 34 & 30.6 & 4 & 3.6 & 0 & 0 \\
\hline 30 & $\begin{array}{l}\text { I am very satisfied with } \\
\text { the VR drawing method } \\
\text { to complete the 3D } \\
\text { design learning. }\end{array}$ & 48 & 43.2 & 39 & 35.1 & 20 & 18 & 4 & 3.6 & 0 & 0 \\
\hline 31 & $\begin{array}{l}\text { I feel very happy that I } \\
\text { can learn 3D design } \\
\text { through VR drawing. }\end{array}$ & 61 & 55 & 37 & 33.3 & 11 & 9.9 & 2 & 1.8 & 0 & 0 \\
\hline
\end{tabular}




\section{References}

1. Renninger, K.A.; Hidi, S. The Power of Interest for Motivation and Engagement; Routledge: New York, NY, USA, 2015.

2. Neo, M.; Neo, K.T.K. Innovative teaching: Using multimedia in a problem-based learning environment. Educ. Technol. Soc. 2001, 4, 19-31.

3. Singh, H. Building effective blended learning programs. Educ. Technol. 2003, 43, 51-54.

4. Lee, Y.-C.; Sun, H.; Chiu, Y.P.; Chiu, P.Y. Gamification: Using game play process for learning $3 \mathrm{~d}$ computer software. ICIC Express Lett. Part B Appl. 2017, 8, 639-646.

5. Mikropoulos, T.A.; Natsis, A. Educational virtual environments: A ten-year review of empirical research (1999-2009). Comput. Educ. 2011, 56, 769-780. [CrossRef]

6. Merchant, Z.; Goetz, E.T.; Cifuentes, L.; Keeney-Kennicutt, W.; Davis, T.J. Effectiveness of virtual reality-based instruction on students' learning outcomes in K-12 and higher education: A meta-analysis. Comput. Educ. 2014, 70, 29-40. [CrossRef]

7. Berney, S.; Bétrancourt, M.; Molinari, G.; Hoyek, N. How spatial abilities and dynamic visualizations interplay when learning functional anatomy with 3D anatomical models. Anat. Sci. Educ. 2015, 8, 452-462. [PubMed]

8. Lorenzo, G.; Lledó, A.; Pomares, J.; Roig, R. Design and application of an immersive virtual reality system to enhance emotional skills for children with autism spectrum disorders. Comput. Educ. 2016, 98, 192-205.

9. Huang, H.-M.; Rauch, U.; Liaw, S.-S. Investigating learners' attitudes toward virtual reality learning environments: Based on a constructivist approach. Comput. Educ. 2010, 55, 1171-1182. [CrossRef]

10. Google Tilt Brush. Available online: https://www.tiltbrush.com/ (accessed on 2 December 2018).

11. Arnaldi, B.; Guitton, P.; Moreau, G. (Eds.) Virtual Reality and Augmented Reality: Myths and Realities; John Wiley \& Sons: Hoboken, NJ, USA, 2018.

12. Gibson, W. Burning Chrome; Hachette: London, UK, 2017.

13. Available online: https://www.vrs.org.uk/virtual-reality-profiles/vpl-research.html (accessed on 13 December 2018).

14. Jerald, J. The VR Book: Human-Centered Design for Virtual Reality; Morgan \& Claypool: San Rafael, CA, USA, 2015.

15. Sherman, W.R.; Craig, A.B. Understanding Virtual Reality: Interface, Application, and Design; Morgan Kaufmann: New York, NY, USA, 2003.

16. Burdea, G.C.; Coiffet, P. Virtual Reality Technology; John Wiley \& Sons: Hoboken, NJ, USA, 2003.

17. Earnshaw, R.A. (Ed.) Virtual Reality Systems; Academic Press: Lodon, UK, 2014.

18. Heim, M. Virtual Realism; Oxford University Press: New York, NY, USA, 2000.

19. Yoh, M.-S. The reality of virtual reality. In Proceedings of the 2001 Seventh International Conference on Virtual Systems and Multimedia, Berkeley, CA, USA, 25-27 October 2001; pp. 666-674.

20. Hew, K.F.; Cheung, W.S. Use of three-dimensional (3-D) immersive virtual worlds in K-12 and higher education settings: A review of the research. Br. J. Educ. Technol. 2010, 41, 33-55.

21. Nugent, W.R. Virtual reality: Advanced imaging special effects let you roam in cyberspace. J. Am. Soc. Inf. Sci. 1991, 42, 609-617. [CrossRef]

22. Ausburn, L.J.; Ausburn, F.B. Effects of desktop virtual reality on learner performance and confidence in environment mastery: Opening a line of inquiry. J. STEM Teach. Educ. 2008, 45, 6.

23. Khanal, P.; Vankipuram, A.; Ashby, A.; Vankipuram, M.; Gupta, A.; Drumm-Gurnee, D.; Josey, K.; Tinker, L.; Smith, M. Collaborative virtual reality based advanced cardiac life support training simulator using virtual reality principles. J. Biomed. Inf. 2014, 51, 49-59. [CrossRef] [PubMed]

24. Levac, D.; Levac, D.; Glegg, S.; Colquhoun, H.; Miller, P.; Noubary, F. Virtual reality and active videogame-based practice, learning needs, and preferences: A cross-Canada survey of physical therapists and occupational therapists. Games Health J. 2017, 6, 217-228. [CrossRef] [PubMed]

25. Chan, S.; Conti, F.; Salisbury, K.; Blevins, N.H. Virtual reality simulation in neurosurgery: Technologies and evolution. Neurosurgery 2013, 72, A154-A164. [CrossRef]

26. Schofield, G.; Beale, G.; Beale, N.; Fell, M.; Hadley, D.; Hook, J.; Murphy, D.; Richards, J.; Thresh, L. Viking VR: Designing a Virtual Reality Experience for a Museum. In Proceedings of the 2018 Designing Interactive Systems Conference, Hong Kong, China, 9-13 June 2018; pp. 805-815. 
27. Subramanian, A.; Barnes, J.; Vemulapalli, N.; Chhawri, S. Virtual Reality Museum of Consumer Technologies. In Advances in Human Factors, Business Management, Training and Education; Springer: Cham, Switzerland, 2017; pp. 549-560.

28. Martin, J.; Ochoa, E.; Villota, W.; Stone, G. Visual Storytelling as a Conservation and Education tool: “Valen's Reef" a Virtual Reality Underwater Diving Experience in Raja Ampat, Indonesia. Div. Sci. 2016, 2016, 136.

29. Schultheiss, P.; Buatois, A.; Avarguès-Weber, A.; Giurfa, M. Using virtual reality to study visual performances of honeybees. Curr. Opin. Insect Sci. 2017, 24, 43-50. [CrossRef] [PubMed]

30. Keller, J.M. Motivation, Learning, and Technology: Applying the ARCS-V Motivation Model. Particip. Educ. Res. (PER) 2016, 3, 1-13. [CrossRef]

31. Mayer, R.E. The promise of multimedia learning: Using the same instructional design methods across different media. Learn. Instr. 2003, 13, 125-139. [CrossRef]

32. Shin, D.-H. The role of affordance in the experience of virtual reality learning: Technological and affective affordances in virtual reality. Telemat. Inform. 2017, 34, 1826-1836. [CrossRef]

33. Potkonjak, V.; Gardner, M.; Callaghan, V.; Mattila, P.; Guetl, C.; Petrović, V.M.; Jovanović, K. Virtual laboratories for education in science, technology, and engineering: A review. Comput. Educ. 2016, 95, 309-327. [CrossRef]

34. Bonde, M.T.; Makransky, G.; Wandall, J.; Larsen, M.V.; Morsing, M.; Jarmer, H.; Sommer, M.O.A. Improving biotech education through gamified laboratory simulations. Nat. Biotechnol. 2014, 32, 694. [CrossRef] [PubMed]

35. Limniou, M.; Roberts, D.; Papadopoulos, N. Full immersive virtual environment CAVE ${ }^{\mathrm{TM}}$ in chemistry education. Comput. Educ. 2008, 51, 584-593. [CrossRef]

36. Kartiko, I.; Kavakli, M.; Cheng, K. Learning science in a virtual reality application: The impacts of animated-virtual actors' visual complexity. Comput. Educ. 2010, 55, 881-891. [CrossRef]

37. Weng, T.; Hsu, M.-H.; Yang, D.-C. A Study investigating the use of 3D computer animations of trigonometric functions to enhance spatial perception ability. Int. J. Inf. Educ. Technol. 2017, 7, 23. [CrossRef]

38. Lee, E.A.-L.; Wong, K.W.; Fung, C.C. How does desktop virtual reality enhance learning outcomes? A structural equation modeling approach. Comput. Educ. 2010, 55, 1424-1442.

39. Höffler, T.N. Spatial ability: Its influence on learning with visualizations-A meta-analytic review. Educ. Psychol. Rev. 2010, 22, 245-269. [CrossRef]

40. Molina-Carmona, R.; Pertegal-Felices, M.L.; Jimeno-Morenilla, A.; Mora-Mora, J. Virtual Reality Learning Activities for Multimedia Students to Enhance Spatial Ability. Sustainability 2018, 10, 1074. [CrossRef]

41. Heydarian, A.; Huang, W.; Sosa, R.; Heydarian, A.; Da Costa Luz Carneiro, J.P.A.; Gerber, D.; Becerik-Gerber, B.; Hayes, T.; Wood, W. Immersive virtual environments: Experiments on impacting design and human building interaction. 2014.

42. Coxon, M.; Kelly, N.; Page, S. Individual differences in virtual reality: Are spatial presence and spatial ability linked? Virtual Real. 2016, 20, 203-212. [CrossRef]

43. Cheng, Y.; Wang, S.-H. Applying a 3D virtual learning environment to facilitate student's application ability-The case of marketing. Comput. Hum. Behav. 2011, 27, 576-584. [CrossRef]

44. Greenwald, S.; Kulik, A.; Kunert, A.; Beck, S.; Frohlich, B.; Cobb, S.; Parsons, S.; Newbutt, N.; Gouveia, C.; Cook, C.; et al. Technology and applications for collaborative learning in virtual reality. In Proceedings of the 12th International Conference on Computer Supported Collaborative Learning (CSCL), Philadelphia, PA, USA, 18-22 June 2017.

45. Huk, T.; Steinke, M.; Floto, C. The influence of visual spatial ability on the attitude of users towards high-quality 3D-animations in hypermedia learning environments. In Proceedings of the E-learn, Phoenix, AZ, USA, 7-11 November 2003; pp. 1038-1041.

46. Huk, T. Who benefits from learning with 3D models? The case of spatial ability. J. Comput. Assist. Learn. 2006, 22, 392-404. [CrossRef]

47. Riecke, B.E.; Laviola, J.R.; Joseph, J.; Kruijff, E. 3D user interfaces for virtual reality and games: 3D selection, manipulation, and spatial navigation. In Proceedings of the ACM SIGGRAPH 2018 Courses. ACM, Vancouver, BC, Canada, 12-16 August 2018; p. 13.

48. Moss, J.D.; Muth, E.R. Characteristics of head-mounted displays and their effects on simulator sickness. Hum. Factors 2011, 53, 308-319. [CrossRef] [PubMed] 
49. Devon, A.; Adrian, V.M. Learning in virtual reality: Effects on performance, emotion and engagement. Res. Learn. Technol. 2018, 26. [CrossRef]

50. Hamrol, A.; Górski, F.; Grajewski, D.; Zawadzki, P. Virtual 3D atlas of a human body-development of an educational medical software application. Procedia Comput. Sci. 2013, 25, 302-314. [CrossRef]

51. Stewart, C.; Crone, T. Maintaining motivation in online students: An examination of the ARCS-V motivation model. In Blended Learning: Concepts, Methodologies, Tools, and Applications; IGI Global: London, UK, 2017; pp. 1472-1509.

52. De Haan, G.; Griffith, E.J.; Post, F.H. Using the Wii Balance Board ${ }^{\mathrm{TM}}$ as a low-cost VR interaction device. In Proceedings of the 2008 ACM Symposium on Virtual Reality Software and Technology, Bordeaux, France, 27-29 October 2008; pp. 289-290.

53. Kammergruber, F.; Ebner, A.; Günthner, W.A. Navigation in virtual reality using Microsoft Kinect. In Proceedings of the 12th International Conference on Construction Applications of Virtual Reality, Taipei, Taiwan, 1-2 December 2012.

54. Craig, A.; Krishnan, S. Fusion of Leap Motion and Kinect Sensors for Improved Field of View and Accuracy for VR Applications. 2016. Available online: http:/ /stanford.edu/class/ee267/Spring2016/report_craig_ krishnan.pdf (accessed on 28 February 2018).

55. Lee, D.; Baek, K.; Lee, J.; Lim, H. A development of virtual reality game utilizing kinect, oculus rift and smartphone. Int. J. Appl. Eng. Res. 2016, 11, 829-833.

(C) 2019 by the authors. Licensee MDPI, Basel, Switzerland. This article is an open access article distributed under the terms and conditions of the Creative Commons Attribution (CC BY) license (http://creativecommons.org/licenses/by/4.0/). 